\title{
Concentração de macronutrientes e metais pesados em maravalha de unidade de suínos em cama sobreposta
}

\author{
Martha M. Higarashi' ${ }^{1}$, Arlei Coldebella ${ }^{1}$, Paulo A. V. de Oliveira ${ }^{1}$, Airton Kunz ${ }^{1}$, \\ Rosemari M. Mattei ${ }^{1}$, Virgínia S. Silva ${ }^{1}$ \& Armando L. do Amaral ${ }^{1}$
}

\begin{abstract}
RESUMO
O setor suinícola brasileiro vem sofrendo severas críticas em virtude da poluição, sobretudo hídrica, constatada nas regiões de maior concentração animal, colocando sob questionamento o modelo produtivo atualmente adotado. Dentro deste contexto, o sistema de criação em cama sobreposta surge como alternativa promissora, uma vez que reduz os riscos de contaminação pela conversão do manejo dos dejetos da fase líquida para a sólida, possibilitando a produção de um composto orgânico comercial que pode gerar renda extra ou viabilizar, na propriedade de origem, a consorciação com a agricultura orgânica. Neste trabalho se avaliou a concentração de macronutrientes (N, P, K), cobre e zinco, na maravalha de quatro baias em uma unidade de produção de cama sobreposta no decorrer de 8 lotes com 70 animais. Cada baia alojou, durante 35 dias, os animais em diferentes fases (idade de entrada: creche $=21, \mathrm{~B} 1=56, \mathrm{~B} 2=91 \mathrm{e}$ B3 = 126 dias). Os resultados mostraram que as concentrações médias de nutrientes das camas atendem às exigências da legislação vigente para fertilizante orgânico simples. A concentração de zinco na cama da creche é cerca de 5 vezes maior que nas demais baias, demonstrando a influência da dieta na composição final do composto.
\end{abstract}

Palavras-chave: suinocultura, dejetos, manejo alternativo, composto orgânico

\section{Concentrations of macronutrients and heavy metal in wood shavings from deep bedding swine facilities}

\begin{abstract}
The swine production industry in Brazil has been severely criticized due to pollution, mainly in water, that has been noticed in regions where swine production is concentrated. This fact puts in question the current production model. Deep bedding system for swine production appears as a promising alternative, because it reduces the risks of contamination by converting manure management from liquid to solid phase. Additionally, it makes possible the production of organic compost, which can generate extra income or can be applied in the same farm to implement an organic agricultural production. This study evaluated the increase of macronutrients, copper and zinc concentrations in wood shavings used as a substrate in four stalls during a period when 8 groups of 70 animals were raised. Each stall had animals installed during 35 days, according to their age of entrance (nursery $=21, S 1=56, S 2=91$ and S3 $=126$ days). Results have shown that average concentrations of nutrients in beds are in compliance with legislation for simple organic fertilizer. The concentration of zinc in the nursery bed was about 5 times higher than other stalls, which shows the influence of diet on the composition of the compost.
\end{abstract}

Key words: swine production, rejects, alternative management, organic compost

Embrapa Suínos e Aves, BR-153, Km 110, Vila Tamanduá, CP 21, CEP 89700-000, Concórdia, SC. Fone: (49) 3441-0400, Fax: (49) $3442-8559$. E-mail:martha@cnpsa.embrapa.br; acoldebe@cnpsa.embrapa.br; paolive@cnpsa.embrapa.br; airton@cnpsa.embrapa.br; martini@cnpsa.embrapa.br; vica@cnpsa.embrapa.br; armando@cnpsa.embrapa.br 


\section{INTRODUÇÃO}

A perspectiva de que o suprimento mundial de água potável se esgote em um futuro próximo, figura entre as principais questões ambientais amplamente debatidas nesta última década.

Estudos conduzidos pela Food and Agriculture Organization of the United Nations (FAO, 2002) demonstraram grande crescimento no consumo mundial de água a partir da década de 50. Outro fato que merece destaque neste estudo é a constatação de que, além do aumento natural decorrente do crescimento populacional, o uso abusivo e indiscriminado, aliado à poluição dos mananciais, tem comprometido seriamente o abastecimento de água em diversas partes do mundo.

Atualmente, as atividades agropecuárias são responsáveis pela maior parcela do consumo de água em quase todas as regiões do planeta, com exceção da Europa e da América do Norte. Em escala mundial, o setor responde por $69 \%$ do consumo, seguido da indústria, com $21 \%$, e o uso para fins domésticos com 10\% (FAO, 2002).

A produção de animais em confinamento é, sem dúvida, uma atividade com alto fator de risco para os recursos hídricos pois, além de demandar grande volume de água para a higienização das instalações e dessedentação dos animais, ainda gera efluentes altamente impactantes (Perdomo et al., 2003).

A prática mais usualmente empregada para o manejo dos efluentes suinícolas consiste no seu armazenamento em depósitos ou lagoas de estabilização, por períodos que variam de acordo com as legislações específicas de cada estado, seguido da sua distribuição integral em lavouras e pastagens. Recentemente, a eficiência de tal manejo tem sido questionada em relação ao alto grau de contaminação muitas vezes encontrado em rios e solos nas regiões de grande concentração de suínos (Palhares et al., 2002).

Assim sendo, o desenvolvimento de tecnologias alternativas que possibilitem a redução da contaminação e da demanda de água nas atividades agropecuárias, constituem-se em avanços estratégicos para evitar o colapso prematuro no abastecimento de água, através da manutenção qualitativa e quantitativa dos recursos hídricos. Dentro desse contexto, o sistema de criação de suínos em cama sobreposta pode ser citado como uma das tecnologias que se enquadram perfeitamente nesse novo tipo de enfoque.

O sistema de cama sobreposta consiste na criação dos suínos sobre um leito composto de um substrato que absorve as dejeções durante a permanência dos animais na unidade de produção. As maiores vantagens do sistema são a eliminação das lavagens regulares dos pisos e a conversão do manejo dos dejetos da fase líquida para a sólida, concentrando os nutrientes e reduzindo os riscos de acidentes (Didier, 1999); outra vantagem que pode ser ressaltada é a redução de 30 a 50\% nos custos de construção das instalações, devido à eliminação das canaletas, pisos e esterqueiras.

Os principais gargalos que impedem a maior difusão do sistema de cama sobreposta se relacionam aos riscos sanitários (Amaral et al., 2002) e ao menor desempenho dos animais em períodos de temperatura elevada (Higarashi et al., 2005).
O maior risco sanitário creditado ao sistema se deve ao fato dos animais permanecerem em contato direto e prolongado com as fezes e a urina do rebanho durante todo o período de alojamento, favorecendo a propagação de eventuais doenças entre os animais do mesmo lote e, no caso de reutilização das camas, o contágio de animais dos lotes precedentes. Em virtude disso, em alguns países se recomenda a troca das camas ao final de cada lote (Moller et al., 2000), o que pode inviabilizar economicamente o sistema, dependendo do custo do substrato utilizado.

A absorção dos dejetos pelas camas, aliada ao revolvimento promovido pela movimentação dos próprios animais, desencadeia o processo de fermentação aeróbia, característico da compostagem de resíduos orgânicos. Este processo é exotérmico, ou seja, libera calor, causando uma elevação significativa na temperatura do substrato.

O fenômeno de aquecimento das camas é benéfico em períodos de inverno rigoroso, pois melhora o conforto dos animais (Honeyman \& Harmon, 2003), além de poder ser utilizado como uma estratégia para reduzir a pressão de infecção pelo controle térmico e exposição à atmosfera desfavorável, visto que a maioria dos microrganismos patogênicos do trato gastrointestinal é termolábil e estritamente anaeróbio; por outro lado, em períodos de temperatura elevada o desempenho animal pode sofrer perdas significativas, haja vista que o calor desprendido pode ocasionar elevação da temperatura ambiente a tal ponto, que esta exceda a zona de conforto térmico.

Embora algumas questões necessitem de ajustes dentro da produção de suínos em cama sobreposta, as inúmeras vantagens apresentadas pelo sistema, aliadas à produção de composto orgânico em substituição ao efluente líquido, tornam o sistema uma proposta bastante interessante, principalmente quando se leva em consideração a existência de uma forte tendência mundial para a criação de leis e barreiras comerciais a produtos cujas cadeias possam gerar a degradação ambiental.

Alavancado por esta mesma tendência, o mercado mundial de alimentos orgânicos se encontra em franca expansão, o que levou o Ministério da Agricultura Pecuária e Abastecimento a estabelecer, recentemente, as definições, normas e padrões para a produção de fertilizantes orgânicos, através da Instrução Normativa nº 23, de 31 de Agosto de 2005 (Brasil, 2005a); assim, para que um composto resultante do processamento de resíduos agropecuários seja considerado um fertilizante orgânico comercial, este deverá atender às especificações legais estabelecidas.

Na Dinamarca, os principais resíduos animais utilizados em fazendas orgânicas são o substrato proveniente de criação de suínos em cama sobreposta e o lodo de esterqueiras (Moller et al., 2000), demonstrando o potencial de tais matrizes no suprimento de nutrientes para este nicho de mercado.

No presente trabalho avaliaram-se a evolução da concentração de macronutrientes (nitrogênio, fósforo e potássio) e dois metais pesados (cobre e zinco) em camas de maravalha ao longo de um ano de instalação de uma unidade de criação de suínos em cama sobreposta, nas fases de creche, crescimento e terminação. 
Os metais, embora sejam elementos essenciais representam, em doses elevadas, riscos ao ambiente e à saúde humana. O cobre e o zinco foram os metais avaliados por serem utilizados na elaboração das rações de suínos como promotores de crescimento e na prevenção da diarréia, respectivamente.

Assim, o monitoramento da concentração dos elementos supracitados durante a utilização das camas, pode servir como balizamento para avaliar o potencial desse substrato como composto orgânico, considerando-se a legislação vigente no Brasil.

\section{MATERIAL E MÉTODOS}

O experimento foi conduzido na Embrapa Suínos e Aves de Concórdia, SC, em uma unidade de produção de suínos em cama sobreposta de dimensões 10 x 30 m, com pé direito de $3 \mathrm{~m}$. O galpão foi preenchido com $0,5 \mathrm{~m}$ de profundidade de maravalha e dividido em quatro baias com diferentes dimensões (creche $=4,5 ; \mathrm{B} 1=6,4$; $\mathrm{B} 2=8,6$ e B3 $=10,5 \mathrm{~m}$ de comprimento), onde foram alojados sucessivamente, 8 lotes de 70 animais/baia (50\% machos castrados e 50\% fêmeas), o que corresponde a aproximadamente um ano de uso das camas.

As divisões foram realizadas com o intuito de fornecer densidades específicas para as diferentes fases de crescimento, sendo que cada animal dispunha de área diferenciada, de acordo com a Tabela 1.

Tabela 1. Área média total e área média de cama disponibilizada por animal alojado, nas diferentes fases de crescimento

\begin{tabular}{lcc}
\hline $\begin{array}{c}\text { Baia } \\
\text { (idade entrada e saída) }\end{array}$ & $\begin{array}{c}\text { Área de Cama + Piso } \\
\text { Compacto }\left(\mathbf{m}^{2}\right)\end{array}$ & Área de Cama $\left(\mathbf{m}^{2}\right)$ \\
Creche (21 a 56 dias) & 0,64 & 0,55 \\
Baia 1 (56 a 91 dias) & 0,91 & 0,78 \\
Baia 2 (91 a 126 dias) & 1,23 & 1,04 \\
Baia 3 (126 a 154 dias) & 1,50 & 1,28 \\
\hline
\end{tabular}

A área de piso compacto citada na Tabela 1, consiste de uma faixa de $1,50 \mathrm{~m}$ construída junto a uma das laterais do galpão, onde foram instalados os bebedouros e comedouros.

Os animais foram pesados e transferidos de baia, em intervalos de 35 dias, permanecendo a baia desalojada pelo período de 7 dias com vazio sanitário, a fim de reduzir a pressão de infecção e evitar a contaminação dos lotes subseqüentes (Morés \& Amaral, 2003). Após a saída dos animais as camas das baias desalojadas foram cuidadosamente revolvidas para promover a aeração e homogeneizar o material.

As amostras de cama de maravalha foram coletadas a cada desalojamento, logo após o revolvimento, aplicando-se a metodologia normatizada para amostragem de solo de áreas contaminadas com distribuição sistemática dos pontos, utilizando-se malha regular (CETESB, 1999).

As subamostras de cada baia foram coletadas para se obter uma amostra composta representativa; as coletas foram superficiais, visto que as camas já haviam sido revolvidas e o número de pontos variou de acordo com as dimensões das baias (creche = 9; B1 =12; B2 = 15 e B3 = 18 pontos).

As amostras foram encaminhadas ao laboratório de análises físico-químicas da Embrapa Suínos e Aves, onde foram processadas e analisadas de acordo com metodologias oficiais (AOAC, 1984; APHA/AWWA/WEF, 1995).

Os parâmetros avaliados foram os macronutrientes Nitrogênio Total Kjeldahl (NTK = N-orgânico + N-amoniacal), Fósforo Total ( $\mathrm{P}_{\text {Total }}$ ), Potássio (K), Carbono Orgânico (CO) e os metais Cobre $(\mathrm{Cu})$ e Zinco $(\mathrm{Zn})$. Em duas amostras de camas foram analisados também Nitrito $\left(\mathrm{NO}_{2}{ }^{-}\right)$e Nitrato $\left(\mathrm{NO}_{3}{ }^{-}\right)$, através do método automatizado de redução por coluna de cádmio.

Os resultados das análises foram avaliados por baia, para verificar se existem diferenças significativas nas concentrações dos nutrientes, de acordo com a densidade animal e a fase de crescimento, considerando-se também que a composição das rações é diferenciada conforme a idade dos animais. Para tal, a análise dos dados foi realizada comparando-se as retas de cada baia em função do lote e se utilizando a teoria de modelos mistos para medidas repetidas e 16 tipos de estruturas de matriz de variâncias e covariâncias através do PROC MIXED do SAS (2003), conforme Xavier (2000). A estrutura de variâncias e covariâncias usada na análise foi escolhida com base no menor valor do Critério de Informação de Akaike (AIC). O método de estimação usado foi o de máxima verossimilhança restrita. As variáveis explicativas do modelo, foram lote, baia e a interação lote $\times$ baia, sendo que o efeito de lote entrou no modelo com uma medida longitudinal e quantitativa, o efeito de lote como fator. Na análise, o intercepto $(\alpha)$ das retas foi considerado o mesmo para todas as baias, dado que não existe justificativa biológica para haver diferenças significativas entre eles, pois o substrato inicial é o mesmo em todas as baias.

Para detalhar as análises estatísticas foram calculados os intervalos de confiança (95\%) para os coeficientes de inclinação das retas $\left(\beta_{\mathrm{s}}\right)$, sendo este intervalo usado para comparar as retas duas a duas, quando a interação entre lote e baia foi significativa $(\mathrm{p}<0,05)$, considerando-se as mesmas significativamente diferentes quando não houvesse sobreposição dos intervalos de confiança. O coeficiente de determinação de cada reta ajustada foi calculado como sendo o quadrado do coeficiente de correlação entre os dados observados e os dados estimados pelo modelo para cada baia.

\section{RESULTADOS E DISCUSSÃO}

Após a passagem de 8 lotes pela unidade de produção de suínos em cama sobreposta, começou-se a observar a formação de áreas com acúmulo de lodo nas baias, principalmente naquelas que alojavam os animais maiores, indicando a necessidade de se iniciar a substituição dos substratos das camas; este fato está em consonância com a recomendação de que, após um ano de utilização, as camas devem ser total ou parcialmente substituídas (Oliveira et al., 2002; Higarashi et al., 2006). 
As formações das áreas com lodo ocorrem em virtude da inibição da fermentação aeróbia causada pela diminuição da relação $\mathrm{C} / \mathrm{N}$, fazendo com que o calor gerado no sistema seja insuficiente para evaporar o excesso de umidade (Groenestein \& van Faassen, 1996). O surgimento do lodo é prejudicial ao sistema, visto que essas áreas são focos de emissão de odores e proliferação de moscas, além de aumentarem significativamente os riscos sanitários (Amaral et al., 2002).

Apresentam-se, na Tabela 2, as estimativas do intercepto $(\alpha)$ e do coeficiente de inclinação $(\beta)$ da reta por baia e o intervalo de confiança (95\%) para $\beta$, bem como os tipos de estruturas de variância e covariância usados para cada variável.

Tabela 2. Estimativas dos parâmetros $(\alpha$ e $\beta$ ) da reta para cada baia, nível descritivo de probabilidade do teste t para $\beta=0$ e intervalo de confiança $(95 \%)$ para $\beta$ e coeficiente de determinação da reta

\begin{tabular}{|c|c|c|c|c|c|c|}
\hline \multirow[t]{2}{*}{ Baia } & \multirow[t]{2}{*}{$\alpha$} & \multirow[t]{2}{*}{$\beta$} & Prob $>|t|$ & \multicolumn{2}{|c|}{$\begin{array}{l}\text { Intervalo de confiança } \\
(95 \%) \text { para } \beta\end{array}$} & \multirow[t]{2}{*}{$\mathbf{R}^{2}$} \\
\hline & & & oro Total (mg & $\left.\mathrm{kg}^{-1}\right)^{1}$ & & \\
\hline Creche & 4086 & 822 & $<0,0001$ & 573 & 1072 & 0,574 \\
\hline baia 1 & 4086 & 1265 & $<0,0001$ & 1015 & 1514 & 0,794 \\
\hline baia 2 & 4086 & 1007 & $<0,0001$ & 758 & 1257 & 0,848 \\
\hline baia 3 & 4086 & 704 & $<0,0001$ & 454 & 953 & 0,918 \\
\hline \multicolumn{7}{|c|}{ Potássio $\left(\mathrm{mg} \mathrm{kg}^{-1}\right)^{2}$} \\
\hline Creche & 8335 & 2345 & $<0,0001$ & 1776 & 2914 & 0,874 \\
\hline baia 1 & 8335 & 2623 & $<0,0001$ & 2054 & 3191 & 0,864 \\
\hline baia 2 & 8335 & 1789 & $<0,0001$ & 1220 & 2358 & 0,903 \\
\hline baia 3 & 8335 & 721 & 0,0151 & 153 & 1290 & 0,763 \\
\hline \multicolumn{7}{|c|}{ Nitrogênio Total Kjeldahl $\left(\mathrm{mg} \mathrm{kg}^{-1}\right)^{3}$} \\
\hline Creche & 9008 & 639 & 0,0152 & 135 & 1144 & 0,741 \\
\hline baia 1 & 9008 & 665 & 0,0120 & 160 & 1170 & 0,534 \\
\hline baia 2 & 9008 & 392 & 0,1221 & -113 & 897 & 0,839 \\
\hline baia 3 & 9008 & -90 & 0,7157 & -595 & 415 & 0,546 \\
\hline \multicolumn{7}{|c|}{ Matéria Orgânica (\%) ${ }^{4}$} \\
\hline Creche & 40,59 & 0,29 & 0,3311 & $-0,31$ & 0,88 & 0,111 \\
\hline baia 1 & 40,59 & $-0,96$ & 0,0028 & $-1,56$ & $-0,37$ & 0,494 \\
\hline baia 2 & 40,59 & $-1,23$ & 0,0003 & $-1,82$ & $-0,63$ & 0,874 \\
\hline baia 3 & 40,59 & $-1,23$ & 0,0003 & $-1,83$ & $-0,63$ & 0,703 \\
\hline \multicolumn{7}{|c|}{ Zinco $\left(\mathrm{mg} \mathrm{kg}^{-1}\right)^{2}$} \\
\hline Creche & 232,6 & 455,8 & $<0,0001$ & 428,1 & 483,5 & 0,971 \\
\hline baia 1 & 232,6 & 55,6 & 0,0004 & 27,9 & 83,2 & 0,951 \\
\hline baia 2 & 232,6 & 35,4 & 0,0144 & 7,7 & 63,1 & 0,948 \\
\hline baia 3 & 232,6 & 39,0 & 0,0077 & 11,3 & 66,7 & 0,914 \\
\hline \multicolumn{7}{|c|}{ Cobre $\left(\mathrm{mg} \mathrm{kg}^{-1}\right)^{4}$} \\
\hline Creche & 118,8 & 37,5 & $<, 0001$ & 25,0 & 50,1 & 0,922 \\
\hline baia 1 & 118,8 & 44,6 & $<, 0001$ & 32,1 & 57,1 & 0,730 \\
\hline baia 2 & 118,8 & 34,2 & $<, 0001$ & 21,7 & 46,8 & 0,861 \\
\hline baia 3 & 118,8 & 17,5 & 0,0082 & 5,0 & 30,1 & 0,930 \\
\hline
\end{tabular}

Estrutura de variâncias e covariâncias utilizada: ${ }^{1}$ Auto-regressiva de ordem 1 média movéis; ${ }^{2}$ Toeplitz; ${ }^{3}$ Auto-regressiva de $1^{\mathrm{a}}$ ordem; ${ }^{4}$ Simetria composta

Salienta-se que houve diferenças significativas $(\mathrm{p}<0,05)$ entre os $\beta_{\mathrm{s}}$ das retas para todos os parâmetros avaliados, exceto para NTK ( $\mathrm{p}=0,0694)$, implicando em que há retas diferentes entre pelo menos duas baias, para a maioria dos parâmetros.

Para $\mathrm{P}_{\text {total}}$, a baia 3 apresentou o menor coeficiente de in- clinação (704 mg kg-1 lote-1), isto é, o menor acúmulo de $\mathrm{P}_{\text {total }}$ no decorrer dos lotes, sendo significativamente diferente ( $<<0,05)$ do $\beta$ da baia 1 (1.265 $\mathrm{mg} \mathrm{kg}^{-1}$ lote $\left.^{-1}\right)$; o mesmo ocorreu para $\mathrm{K}$ sendo que neste mineral a baia 3 foi significativamente diferente da creche e da baia 1; esses dois nutrientes não apresentam restrições legais quanto ao seu teor em fertilizantes orgânicos; portanto, a sua aplicação e dosagem devem seguir as recomendações agronômicas usuais para cada tipo de solo e cultura. A Figura 1 descreve o comportamento de acúmulo dos nutrientes e metais, ao longo da passagem dos lotes.

O comportamento do NTK (Figura 1C) se diferencia do $\mathrm{P}_{\text {Total }}$ (Figura 1A) e do K (Figura 1B) por apresentar um aumento de concentração proporcional menos pronunciado ao longo dos lotes.

As causas mais prováveis para este comportamento podem ser creditadas às perdas atmosféricas do Nitrogênio Amoniacal $\left(\mathrm{N}-\mathrm{NH}_{3}\right)$, cuja volatilização é intensificada pelo incremento da temperatura das camas, decorrente da fermentação aeróbia.

A teoria das perdas atmosféricas é reforçada quando se verifica que o acúmulo de NTK nas camas dos animais maiores parece ocorrer mais lentamente, apesar de não existir diferenças significativas entre os $\beta_{\mathrm{s}}(\mathrm{p}=0,0694)$. Como os animais maiores possuem maior capacidade de revolver as camas, a aeração é mais eficiente e, portanto, as perdas atmosféricas seriam mais pronunciadas; este fato está em consonância com Oliveira (1999), segundo o qual o aumento de temperatura nas camas de animais de maior peso é superior ao dos animais menores.

Outro fator que poderia contribuir para a diferenciação no comportamento de acúmulo de NTK nas camas, diz respeito às reações de nitritação e nitrificação, ou seja, a conversão do $\mathrm{NH}_{3}$ para $\mathrm{NO}_{2}{ }^{-}$e/ou $\mathrm{NO}_{3}{ }^{-}$. Como essas reações ocorrem por vias aeróbias, quanto maior a aeração/revolvimento, maior também a probabilidade de que ocorra conversão.

Para verificar a ocorrência ou não dessa conversão, fezse a determinação de $\mathrm{NO}_{2}{ }^{-}$e $\mathrm{NO}_{3}{ }^{-}$nas camas do último lote (8) das baias 2 e 3 (com animais maiores). Os resultados das análises demonstraram que a concentração de nitrogênio, tanto na forma de $\mathrm{NO}_{3}{ }^{-}$como de $\mathrm{NO}_{2}^{-}$, em ambas as amostras, ficou abaixo do limite de detecção da metodologia empregada (<0,6 mg kg-1 de composto); portanto, o menor acúmulo proporcional de nitrogênio nas camas se deve às perdas de $\mathrm{NH}_{3}$ para a atmosfera.

A redução progressiva do CO nas camas se deve à mineralização da matéria orgânica pelo processo de fermentação aeróbia facultativa, causando o desprendimento de carbono na forma de gases $\left(\mathrm{CO}_{2}\right.$, $\mathrm{CO}$ ou $\left.\mathrm{CH}_{4}\right)$. De acordo com a Figura 1D, todas as amostras apresentaram concentrações de CO superiores ao mínimo exigido pela Legislação (20\%); no entanto se verifica que nas camas dos animais maiores (Baias 1 , 2 e 3) ocorreram as maiores reduções do CO sendo que, praticamente, não ocorreu redução na cama dos animais da creche; este resultado demonstra novamente que a menor capacidade de revolvimento dos animais mais jovens limita o processo de compostagem. 
A.

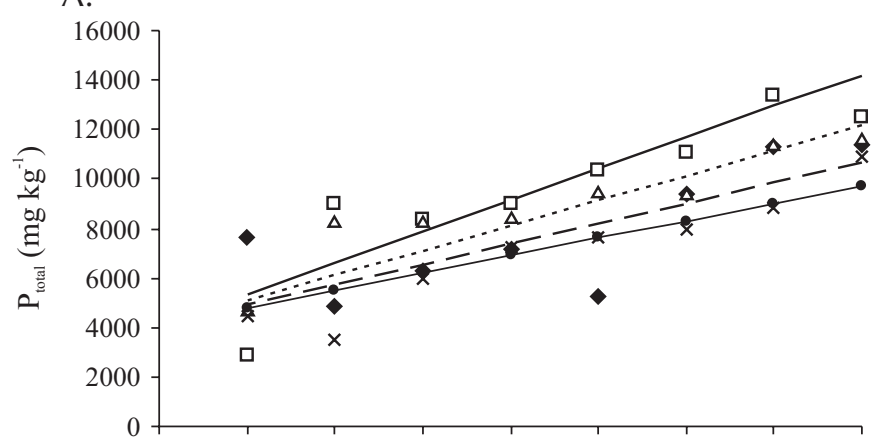

C.

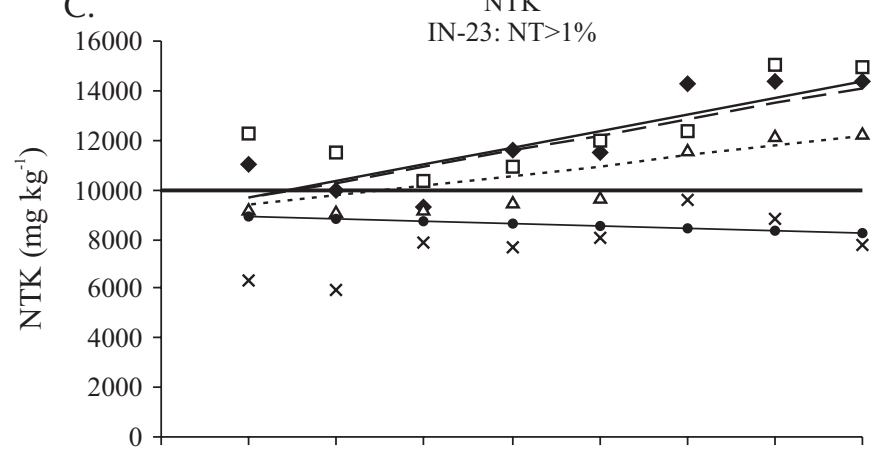

E.

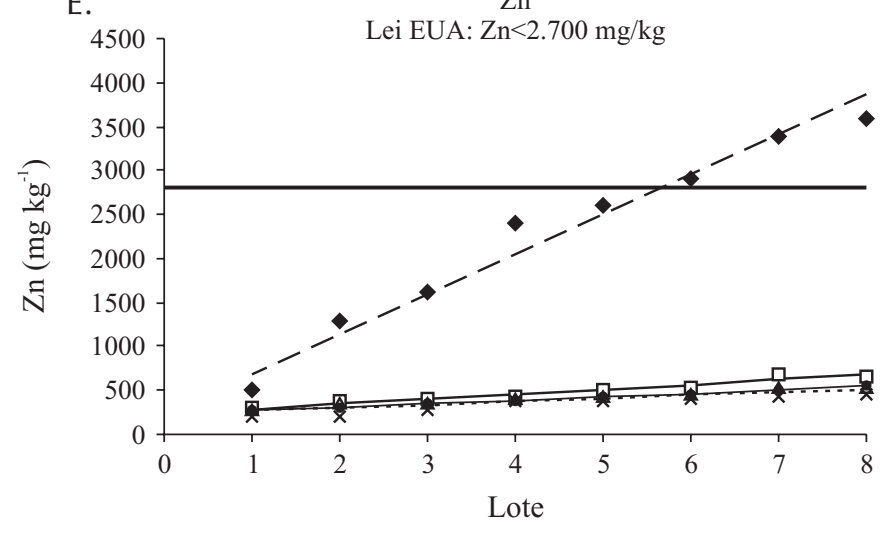

B.

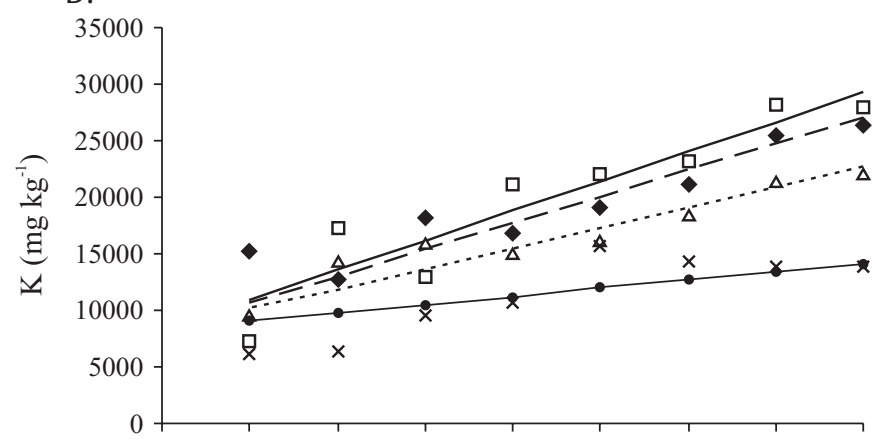

D.

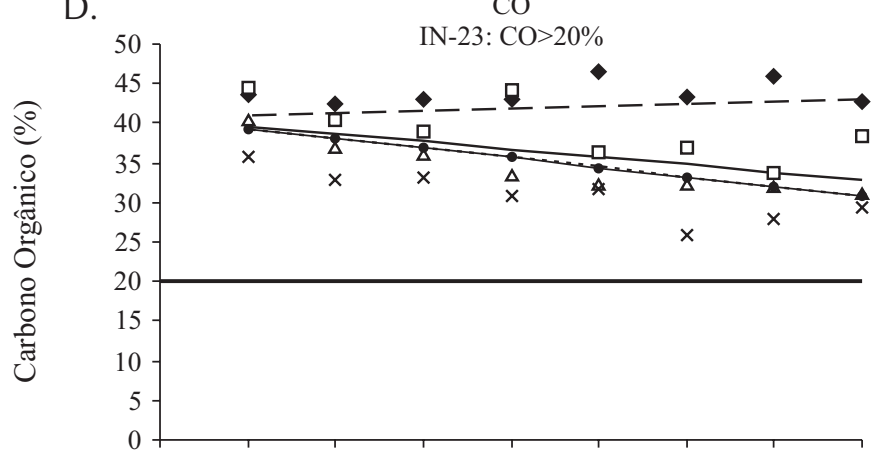

F.

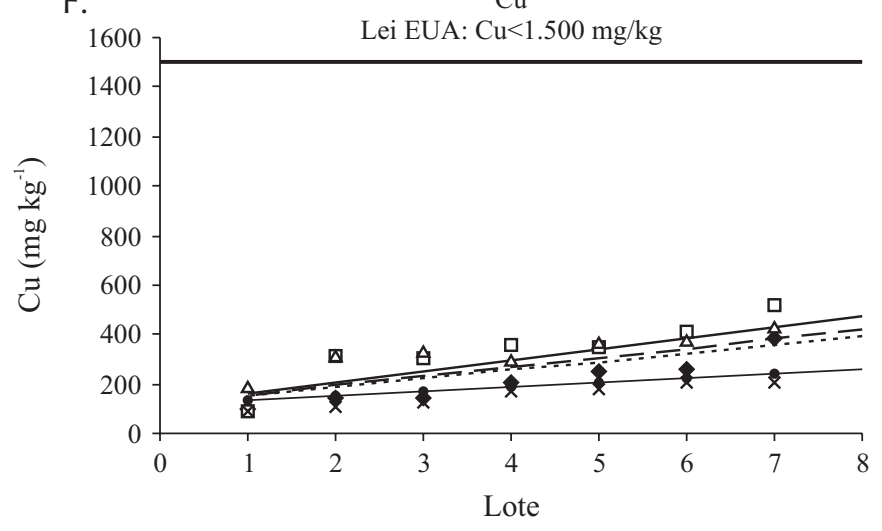

ㅁ baia 1

baia 1 est.

baia 3 est.
$\Delta \quad$ baia 2

-...- baia 2 est.

— Legislação

Figura 1. Evolução observada e estimada da concentração de A. fósforo total ( $\mathrm{P}$ ) B. potássio (K), C. nitrogênio total Kjeldahl (NTK), D. carbono orgânico, E. zinco $(\mathrm{Zn})$ e F. cobre $(\mathrm{Cu})$ na maravalha utilizada nas camas no decorrer de oito lotes de 70 animais nas diferentes fases de crescimento, alojadas nas quatro baias avaliadas

Seria recomendável, portanto, a realização de manejos diferenciados de acordo com o tamanho dos animais, aumentando a freqüência do revolvimento das camas nas baias dos animais menores (semanalmente na creche), a fim de promover a compostagem e a estabilização do material.

Outra medida importante é o estabelecimento de um período sem a presença dos animais, para que as camas passem por uma compostagem adicional antes de serem utilizadas como fertilizantes, a fim de reduzir a umidade e assegurar a eliminação de eventuais patógenos.

$\mathrm{O} \mathrm{Cu}$ apresentou comportamento cumulativo similar aos demais nutrientes, com concentrações finais variando entre 200 a $400 \mathrm{mg} \mathrm{kg}^{-1}$ (Figura 1F). O Zn (Figura 1E), por sua vez, apresenta concentração muito mais alta na creche (cerca de $3.000 \mathrm{mg} \mathrm{kg}^{-1}$ ), comparativamente às demais fases (entre 450 a $680 \mathrm{mg} \mathrm{kg}^{-1}$ ). A causa dessa disparidade no comportamento se deve à composição das rações fornecidas nas diferentes fases dos leitões, uma vez que o zinco é utilizado na prevenção da diarréia, à qual os animais jovens estão mais susceptíveis.

De acordo com os intervalos de confiança, para os coeficientes de inclinação as baias que apresentam comportamento mais semelhante são a 1 e a 2, já esperado, uma vez que ambas as baias alojam animais em fases de crescimento, enquanto a baia 3 aloja os animais em fase de terminação, período no qual a excreção é cerca de $10 \%$ menor (Sobestiansky et al., 1998). 
A creche também apresentou comportamento diferenciado no acúmulo de nutrientes; estas diferenças podem ser decorrentes da própria idade dos animais (metabolismo e menor capacidade de movimentação das camas) como também composição da ração, sendo que a influência deste último se torna bastante evidenciada quando se avaliam os dados referentes ao zinco.

De acordo com a Instrução Normativa $n^{\circ} 23$, para que as camas possam ser classificadas como Fertilizante Orgânico Simples (estercos e camas), elas deverão satisfazer as seguintes especificações: umidade máxima 30\%; pH mínimo conforme declarado (etiqueta); Carbono Orgânico (CO) mínimo 20\%; Nitrogênio Total (NT) mínimo 1\% e Capacidade de troca Catiônica/Carbono (CTC/C) mínimo de 10.

Na Figura 1C pode-se observar que para os animais menores (creche, baias 1 e 2) e a partir do segundo lote, a concentração de NTK (N-NH$+\mathrm{N}_{3}+\mathrm{N}$-orgânico) já atinge o valor mínimo recomendado pela Lei para $\mathrm{NT}\left(\mathrm{NTK}+\mathrm{N}-\mathrm{NO}_{3}+\right.$ $\mathrm{N}-\mathrm{NO}_{2}$ ). Somente na cama da baia 3 (animais maiores), o valor não atingiu os teores exigidos devido às perdas atmosféricas.

A Legislação Brasileira não apresenta valores máximos permitidos para metais pesados em composto orgânico, embora já exista uma portaria que submete à consulta pública o Projeto de Instrução Normativa que estabelece esses limites para os metais pesados cádmio, chumbo, mercúrio, níquel e cromo (Brasil, 2005b); desta forma, não há uma referência nacional para os limites de $\mathrm{Cu}$ e $\mathrm{Zn}$; entretanto, se forem utilizados, como referencial, os limites estabelecidos pela legislação dos Estados Unidos $\left(\mathrm{Cu}=1.500 \mathrm{mg} \mathrm{kg}^{-1} \mathrm{e}\right.$ $\mathrm{Zn}=2.800 \mathrm{mg} \mathrm{kg}^{-1}$ ), pode-se verificar que somente o valor de $\mathrm{Zn}$ na creche se apresenta acima do limite recomendado.

Ao final do experimento (8 lotes), as camas apresentaram certa variação na concentração de nutrientes nas diferentes baias. A Tabela 3 mostra a média ponderada da concentração de NPK das camas retiradas da unidade de produção, considerando-se o volume correspondente a cada baia, a fim de se verificar o valor fertilizante do material, como um todo.

Tabela 3. Valor estimado de concentração de NPK do composto obtido do sistema de cama sobreposta

\begin{tabular}{cc}
\hline Nutriente & Média Ponderada Concentração $\left.\mathbf{( g ~} \mathbf{~ k g}^{-1}\right)$ \\
NTK & 11,6 \\
$\mathrm{P}_{\text {Total }}$ & 11,5 \\
$\mathrm{~K}$ & 21,0 \\
\hline
\end{tabular}

Os valores mostrados na Tabela 3 são semelhantes aos dados encontrados na literatura; Texier \& Levasseur (2003), por exemplo, obtiveram concentrações de NTK = 10,5; $\mathrm{P}_{\text {To- }}$ tal $=12,7$ e $\mathrm{K}=18,7 \mathrm{~g} \mathrm{~kg}^{-1}$ em uma cama de maravalha proveniente de uma unidade de produção de suínos na qual haviam sidos alojados 2 lotes de 40 animais $\left(1,17 \mathrm{~m}^{2}\right.$ por animal) no decorrer de um ano; portanto, mesmo com a utilização de manejos diferentes, as camas utilizadas pelo período de um ano atendem, de maneira geral, às exigências da legislação brasileira vigente.

\section{CONCLUSÕES}

1. O processo de compostagem das camas é limitado pela capacidade dos animais menores movimentarem o substrato (menor aeração das camas da creche).

2. O balanço adequado na formulação da ração, a densidade e a excreção diferenciada de acordo com a idade dos animais, influenciam a qualidade do composto.

3. Apesar dos fatores supracitados, em média as camas utilizadas durante 1 ano (8 lotes) se enquadram na legislação brasileira como fertilizantes orgânicos simples.

\section{AGRADECIMENTOS}

À FINEP/FUNCITEC pelo apoio financeiro e às parceiras do projeto de pesquisa: EPAGRI, UFSC, UNOESC e FUNDAGRO.

\section{LITERATURA CITADA}

Amaral, A. L.; Morés, N.; Ventura, L. V. Ocorrência de linfadenite por mycobacterium avium em suínos criados em cama de maravalha sobreposta. In: Congresso Latino Americano de Suinocultura, 1, 2002, Foz do Iguaçu. Anais...Concórdia: Embrapa Suínos e Aves, 2002. p.57-58.

AOAC - Association of Official Analytical Chemists International (Washington, EUA). Official Methods of Analysis. 14.ed. Washington, DC: Arlington. 1984. p.1.141.

APHA/AWWA/WEF. Standard methods for the examination of water and wastewater. 19.ed. Washington, D.C.: American Public Health Association, 1995. 1.368p.

Brasil. Ministério da Agricultura Pecuária e Abastecimento. Secretaria de Defesa Agropecuária. Instrução Normativa n. 23, de 31 de Agosto de 2005. Diário Oficial da República Federativa do Brasil. Poder Executivo, Brasília, 08 de set. 2005a. Seção 1, p.12.

Brasil. Ministério da Agricultura Pecuária e Abastecimento. Secretaria de Defesa Agropecuária. Portaria n. 49, de 25 de Abril 2005. Diário Oficial da República Federativa do Brasil, Poder Executivo, Brasília, 27 abr. 2005b. Seção 1, p.20.

CETESB - Companhia de Tecnologia de Saneamento Ambiental. Metodologia 6300 - Amostragem do solo. In: Projeto CETESB-GTZ. 1999.

Didier, S. Composting of pigs waste in deep litter systems. Revue de Medecine Veterinaire, v.150, n.6, p.499-510, 1999.

FAO - Food and agriculture organization of the United Nations. Crops and Drops - making the best use of water for agriculture. Roma: FAO, 2002. 22p.

Groenestein, C. M.; van Faassen, H. G. Volatilization of ammonia, nitrous oxide and nitric oxide in deep-litter systems for fattening pigs. Journal of Agricultural Engineering Research, v.65, n.4, p.269-274, 1996.

Higarashi, M. M.; Oliveira, P. A. V.; Amaral, A. L.; Coldebella, A.; Silva, V. S.; Ventura, L.; Mendes, G. L.; Rangel, K. A. Avaliação de sete lotes de suínos em fase de crescimento e terminação criados sobre leito de maravalha. Reunião Anual da SBZ, 2005, Goiânia. Anais... Goiânia: Sociedade Brasileira de Zootecnia, 2005. CD-Rom. 
Higarashi, M. M.; Oliveira, P. A. V.; Silva, V. S.; Amaral, A. L. Recomendações de manejo de sistema de cama sobreposta nas fases de crescimento e terminação. Concórdia: Embrapa CNPSA, 2006. 8p. Comunicado Técnico 430.

Honeyman, M. S.; Harmon, J. D. Performance of finishing pigs in hoop structures and confinement during winter and summer. Journal of Animal Science, v.81, p.1.663-1.670, 2003.

Moller, H. B.; Sommer, S. G.; Andersen, B.H. Nytrogen mass balance in deep litter during the pig fattening cycle and during composting. Journal of Agricultural Science, v.135, p. 287-296, 2000.

Morés, N.; Amaral, A. L. Planejamento da produção com vazio sanitário entre lotes. Concórdia: Embrapa CNPSA, 2003. 4p. Comunicado Técnico 325

Oliveira, P. A. V. Comparaison des systèmes d'élevage des porcs sur litière de sciure ou caillebotis intégral. France: l' ENSA de Rennes. 1999. 272p. Tese Doutorado

Oliveira, P. A. V.; Mendes, G. L.; Nunes, M. L. A. Viabilidade técnico-econômica da produção de suínos em cama sobreposta. Simpósio sobre Manejo e Nutrição de Aves e Suínos e Tecnologia da Produção de Rações, 2002, Campinas. Anais... Campinas: CBNA, 2002. p.89-102.
Palhares, J. C. P.; Barioni Júnior, W.; Jacob, A. D.; Perdomo, C. C. Impacto ambiental da concentração de suínos na bacia hidrográfica do rio Fragosos. Concórdia: Embrapa CNPSA, 2002. 8p. Comunicado Técnico 307

Perdomo, C. C.; Oliveira, P. A. V.; Kunz, A. Metodologia sugerida para estimar o volume e a carga de poluentes gerados em uma granja de suínos. Concórdia: Embrapa CNPSA, 2003. 6p. Comunicado Técnico 332

SAS Institute Inc. System for Microsoft Windows, Release 9.1, Cary, 2002-2003. CD-Rom.

Sobestiansky, J.; Wentz, I.; Silveira, P. R. S.; Sesti, L. A. C. (ed.) Suinocultura intensiva: Produção, manejo e saúde do rebanho. Brasília: Embrapa SPI; Concórdia: Embrapa Suínos e Aves, 1998. 388p.

Texier, C.; Levasseur, P. Les rejets d'azote, phosphore, potassium, cuivre et zinc des porcs engraissés sur caillebotis ou litière de bois. Techni-Porc, v.26, p.9-17, 2003.

Xavier, L. H. Modelos univariado e multivariado para análise de medidas repetidas e verificação da acurácia do modelo univariado por meio de simulação. Piracicaba: ESALQ/USP. 2000. 91 p. Dissertação Mestrado 